\title{
Carotenoid Cleavage Dioxygenase 4 Catalyzes the Formation of Carotenoid Derived Volatile $\beta$-ionone During Tea (Camellia sinensis) Withering
}

Jingming Wang a,b, Na Zhang a,b, Minyue Zhao ${ }^{a, b}$, Tingting Jing a,b, Jieyang Jin a,b, Bin Wu ${ }^{\text {a,b }}$, Xiaochun Wan a,b, Wilfried Schwab ${ }^{\text {a,b,c }}$, Chuankui Song a,b,*.

a, State Key Laboratory of Tea Plant Biology and Utilization, Anhui Agricultural University, 130 Changjiang Ave W., Hefei, Anhui 230036, People's Republic of China. b, International Joint Laboratory on Tea Chemistry and Health Effects, Anhui Agricultural University, 130 Changjiang Ave W., Hefei, Anhui 230036, People's Republic of

China.

c, Biotechnology of Natural Products, Technische Universität München, LieselBeckmann-Str. 1, 85354 Freising, Germany.

*To whom correspondence should be addressed. E-mail: sckfriend@163.com 
Table S1. The primers used for real-time RT-PCR .

\begin{tabular}{ccc}
\hline Gene & Forward & Reverse \\
\hline CCD1a & TGTCCTTCCACGGTATGCAA & GCTTTTCTTTGACAGGCCCA \\
CCD1b & TGTGGGCTTTACCATACGGA & AACTCCCGGCCAATTACTGA \\
CCD1c & AAGGTAAAGACGCCCATA & TCTTGGGGCTTGGATTCG \\
CCD4 & GGAGCGTACATCCGCAACGG & AGATTTTGATGGCGTGGAGCA \\
\hline
\end{tabular}


Table S2. The primers used for the cloning of $C s C C D 4$

\begin{tabular}{cll}
\hline Gene & \multicolumn{1}{c}{ Forward } & \multicolumn{1}{c}{ Reverse } \\
\hline CCD4 & GGATCTGGTTCCGCGTGGATCCAT & GCTCGAGTCGACCCGGGTTAGA \\
& GGATGCCTTCTCATCCTCAT & GCTTGTTGAGGTCGC \\
& & \\
\hline
\end{tabular}




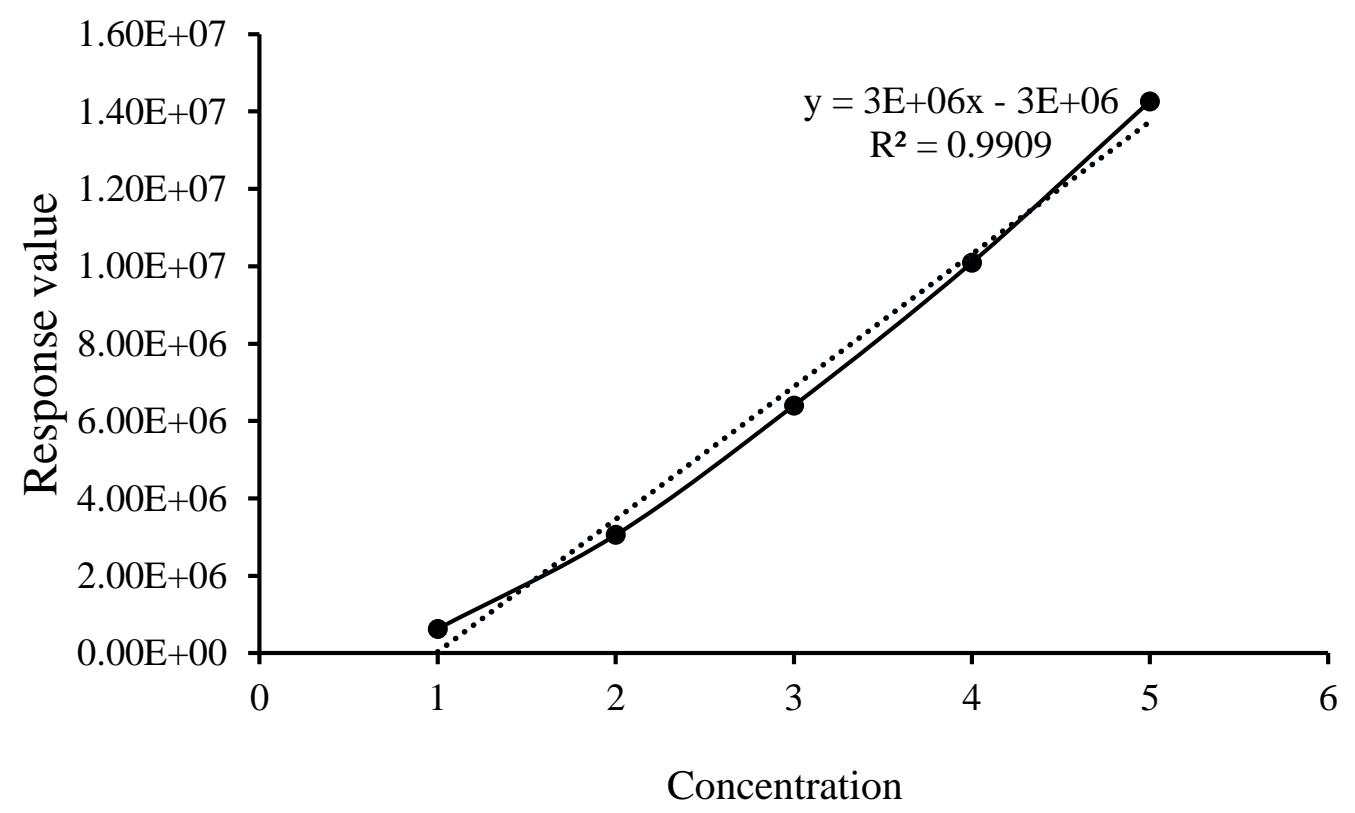

Figure S1. Calibration curves of $\beta$-ionone standard. The concentrations are $0.125 \mathrm{ppm}$, $0.25 \mathrm{ppm}, 0.5 \mathrm{ppm}, 0.75 \mathrm{ppm}, 1 \mathrm{ppm}$, respectively. 